\title{
The Research on the Influencing Factors of China's Urban Economic Development based on Structural Equation Model
}

\author{
Zhou Mei \\ North China University of Technology \\ Beijing, China
}

\author{
Chai $\mathrm{Na}$ \\ North China University of Technology \\ Beijing, China
}

\begin{abstract}
Since the reform and opening up, China's economy has shown a steady upward momentum of development and how to maintain sustained and stable economic growth is our concern. Using the annual data of 2013 China's 31 provinces as samples to set up the structural equation model. The author divide into three aspects for these factors which are effect the economic development of the city, which include transportation, urban construction and people's life. The results show that all of the three aspects have significant effect to urban economic development. Then we put forward constructive opinions to promoting the economic development of the city.
\end{abstract}

Key words Structural equation model, Economic development, Path coefficient

\section{INTRODUCTION}

Since the large open, high investment, and development of the reform, China's economic development has made remarkable achievements and become second largest economy in the world. With the continuous development of economic system reform, China's economy also quietly changing and the various provinces also have earth-shaking changes in economic volume, urban and rural areas and the standard of living. But based on China's national conditions and in a changing international environment backdrop, China as a developing country with the emergence of the development of unbalanced, uncoordinated and widening gap in income distribution and other issues, how to continue to accelerate China's sustained economic development is the need for concern.
Many domestic scholars discuss the factors which affecting the development of the economy. Li Wei, Zhu Weina ${ }^{[1]}$ divided into the total amount and structural factors effecting the regional economic development. Analysis showed that the total amount of factors and structural factors of economic development has a significant impact. Cheng Yan, Mei Shue ${ }^{[2]}$ use structural equation model to analyze the relationship between the technological progress, county economic development and social development in 2009 the county (city) assessment. He Weijun, Shen Changgeng and Yuan Liang ${ }^{[3]}$ use AMOS software build a structure equation about the effect of physical capital and human capital to economic growth. It concludes that physical capital, human capital play significant role in promoting economic growth.

\section{EMPIRICAL ANALYSIS ON THE INFLUENCE OF CHINA'S ECONOMIC DEVELOPMENT}

\section{A. Select variables}

With the help of structural equation model, we make a study about the factors effecting regional economic development. We select the annual data in 201331 provinces of China to do an empirical research using AMOS 21.0. The latent variables we selected have transportation situation, urban construction conditions, People's living conditions and economic development. This paper studied the data are from the National Bureau of Statistics website: http://data.stats.gov.cn/. Correspondence between the set of structural equation latent variables and observed variables are shown in TABLE I. 
TABLE I The correspondence of latent variables and observed variables

\begin{tabular}{|c|c|c|c|}
\hline \multicolumn{2}{|c|}{ Latent Variables } & \multicolumn{2}{|l|}{ Observed variables } \\
\hline \multirow{3}{*}{ Transport } & \multirow{3}{*}{$\mathrm{F} 1$} & passenger volume (million) & $\mathrm{x} 1$ \\
\hline & & freight volume (million tons) & $\mathrm{x} 2$ \\
\hline & & $\begin{array}{l}\text { transportation, storage and postal industry total social fixed } \\
\text { assets investment(billion yuan) }\end{array}$ & $\mathrm{x} 3$ \\
\hline \multirow{3}{*}{$\begin{array}{l}\text { Urban } \\
\text { construction }\end{array}$} & \multirow{3}{*}{$\mathrm{F} 2$} & Urban construction land area (square kilometers) & $\mathrm{x} 4$ \\
\hline & & urban population density (people / square kilometers) & $\mathrm{x} 5$ \\
\hline & & road length (million kilometers) & $\mathrm{x} 6$ \\
\hline \multirow{4}{*}{$\begin{array}{l}\text { People's living } \\
\text { standards }\end{array}$} & \multirow{4}{*}{$\mathrm{F} 3$} & urban residents per capita disposable income (yuan) & $\mathrm{x} 7$ \\
\hline & & rural residents per capita disposable income (yuan) & $\mathrm{x} 8$ \\
\hline & & $\begin{array}{l}\text { balance of urban and rural residents' savings deposits in the } \\
\text { end of the year (billion yuan) }\end{array}$ & x9 \\
\hline & & resident consumption level(yuan) & $\mathrm{x} 10$ \\
\hline \multirow{2}{*}{$\begin{array}{c}\text { Economic } \\
\text { development }\end{array}$} & \multirow{2}{*}{$\mathrm{F} 4$} & GDP (billion) & $\mathrm{x} 11$ \\
\hline & & local general budget revenue (million)) & $\mathrm{x} 12$ \\
\hline
\end{tabular}

\section{B. Model construction}

\section{1) Assumptions of model}

a) There is a positive impact on transport status to economic development.

b) The impact of urban infrastructure and municipal facilities to economic development is positive.

c) People's living conditions have a positive impact on the urban economic development. capacity, urban construction and people's living.

\section{2) Preliminary structural equation model}

The fallowing Fig.1 shows a standardized structural equation model based on 12 measurable variable and 4 latent variables. In particular, the path coefficient between $\mathrm{x} 5$ and the urban construction is the smallest than others and we can consider eliminating it. And the relationship between other potential variables and measurable variables was significant.

d) There are interactions between transportation

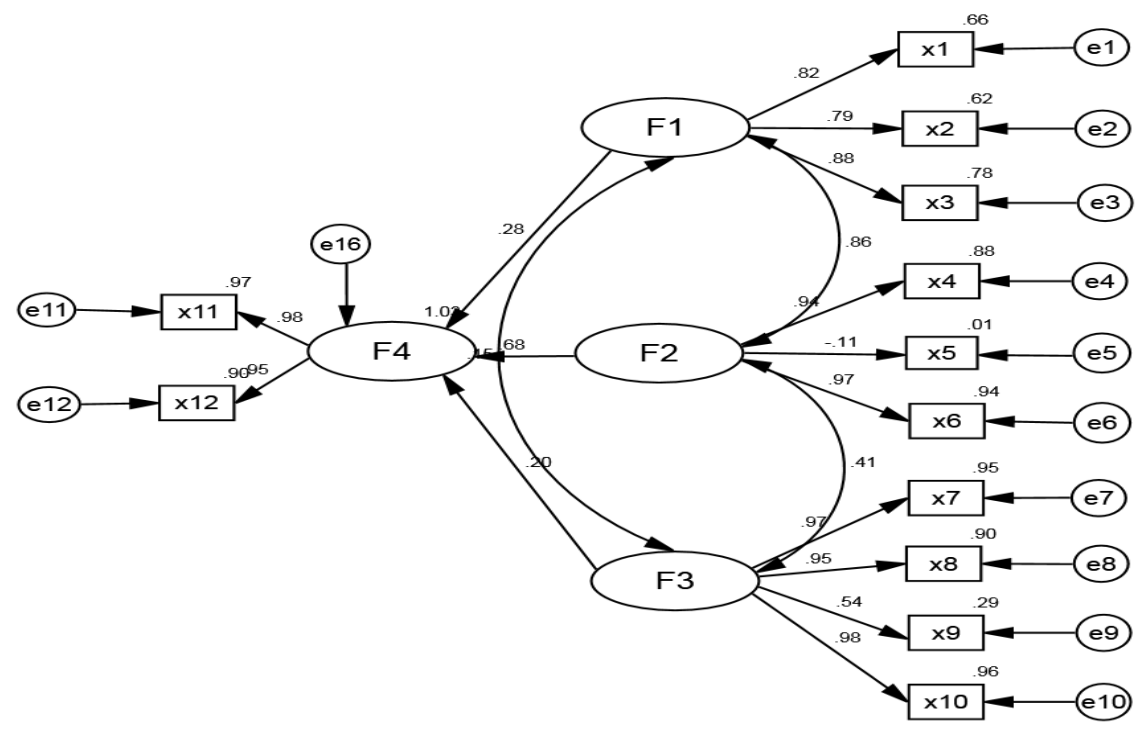

Fig. 1. Standard structural equation model 
It is clearly to see from above TABLE II that the coefficient estimated between $\mathrm{x} 5$ and $\mathrm{F} 2$ is -0.13 and $\mathrm{P}$ value of critical ratio test is 0.557 . The $\mathrm{P}$ value is more than 0.1 , which indicates the coefficient estimate is not significant.

TABLE II Estimate of coefficient test

\begin{tabular}{|c|c|c|c|c|c|c|c|c|c|c|c|}
\hline & Estimate & S.E. & C.R. & $\mathrm{P}$ & Label & & Estimate & S.E. & C.R. & $\mathrm{P}$ & Label \\
\hline economic<---F1 & 0.011 & 0.005 & 2.406 & 0.016 & par_7 & x7<---F3 & 1 & & & & \\
\hline economic<----F3 & 0.049 & 0.018 & 2.756 & 0.006 & par_13 & x8<---F3 & 0.515 & 0.038 & 13.472 & $* * *$ & par_4 \\
\hline economic<---F2 & 1.08 & 0.209 & 5.178 & $* * *$ & par_14 & x9<---F3 & 0.94 & 0.272 & 3.46 & $* * *$ & par_5 \\
\hline x1<---F1 & 1 & & & & & x10<---F3 & 1.128 & 0.068 & 16.607 & $* * *$ & par_6 \\
\hline x2<---F1 & 1.879 & 0.373 & 5.033 & $* * *$ & par_1 & x12<---F4 & 1 & & & & \\
\hline x3<---F1 & 0.014 & 0.002 & 5.922 & $* * *$ & par_2 & x11<---F4 & 9.813 & 0.69 & 14.224 & $* * *$ & par_10 \\
\hline $\mathrm{x} 4<---\mathrm{F} 2$ & 1 & & & & & x $5<---F 2$ & -0.13 & 0.222 & -0.588 & 0.557 & par_11 \\
\hline x6<---F2 & 0.001 & 0 & 12.081 & $* * *$ & par_3 & & & & & & \\
\hline
\end{tabular}

TABLE III represents the model fitting results. There are five indexes which are NFI, RFI, IFI, TLI and CFI. All the indicators' value of the model is between 0.5 and 0.8 that indicate the model fitting effect. And the value of RMSEA of the fit model is 0.2 more than 0.1 . For this model the value of the model is up to 254.827 and the numerical value is larger and higher than the saturation model and the independent model. To sum up, we find that the model fitting is poor and it needs to be corrected.

TABLE III Result of fitting model

\begin{tabular}{|c|c|c|c|c|c|c|}
\hline NFI & RFI & IFI & TLI & \multirow{2}{*}{ CFI } & \multirow{2}{*}{ RMSEA } & AIC \\
\cline { 1 - 4 } Delta1 & rho1 & Delta2 & rho2 & & & \\
\cline { 1 - 3 } 0.725 & 0.622 & 0.786 & 0.696 & 0.779 & 0.292 & 254.827 \\
\hline
\end{tabular}

TABLE IV is a correction table. The model can be modified by the index M.I. in table 4. We know the M.I. value of $\mathrm{x} 9<---\mathrm{F} 1$ for this path is the maximum, so we can get rid of the constraint of the correlation coefficient of the two error terms to 0 of the model.

TABLE IV Correction factor table

\begin{tabular}{|c|c|c|c|c|c|}
\hline & M.I. & Par Change & & M.I. & Par Change \\
\hline x12<---F3 & 9.81 & 0.048 & x9<---x6 & 9.05 & 3408.966 \\
\hline x9<---F2 & 21.363 & 7.883 & x9<---x4 & 5.254 & 2.058 \\
\hline x9<---F1 & 26.53 & 0.225 & x9<---x3 & 5.374 & 3.134 \\
\hline x9<---F4 & 19.068 & 4.654 & x9<---x2 & 5.804 & 0.025 \\
\hline x9<---x11 & 7.633 & 0.178 & x9<---x1 & 5.724 & 0.048 \\
\hline x9<---x12 & 5.231 & 1.367 & $\mathrm{x} 4<---\mathrm{F} 3$ & 6.025 & 0.026 \\
\hline
\end{tabular}

Fig.2 shows that the modified path diagram which is based on standard model. It is the best fitting model due to eliminate $\mathrm{x} 5$ and based on the values of modified index from large to small. We can see there is a significant correlation between latent variables, which is also verified fitting effect of the modified model is better. 


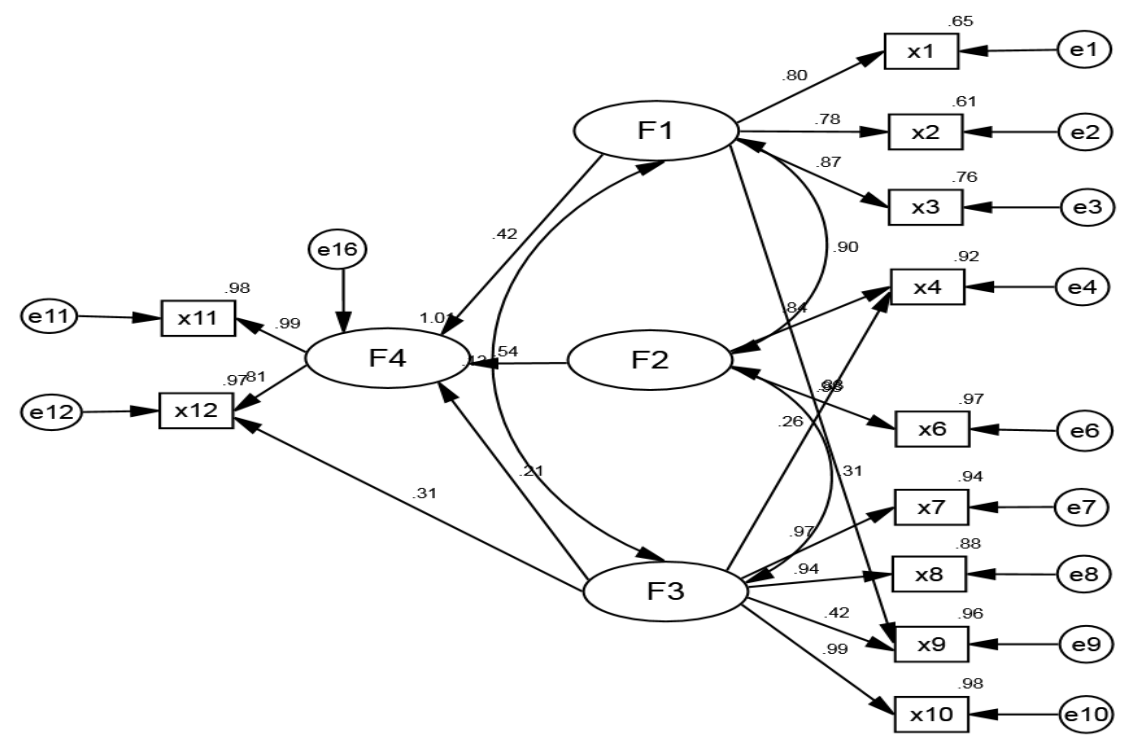

Fig. 2. Modified path graph

TABLE $\mathrm{V}$ shows the modified model fitting results table. From it we can see that the value of CMIN is 37.063, and all of the value of NFI, RFI, IFI, TLI and CFI are greater than 0.9. In addition, RMSEA's value is 0.04 which is less than 0.05 and the value of AIC is 121.063 which is less than the saturated model and independent model. Comprehensive above indicators we found the model fitting is very good and can be further analyze.

\begin{tabular}{|c|c|c|c|c|c|c|c|}
\hline & & TABLE & The fitti & results of & odified $\mathrm{m}$ & & \\
\hline \multirow{2}{*}{ CMIN } & NFI & RFI & IFI & TLI & \multirow{2}{*}{ CFI } & \multirow{2}{*}{ RMSEA } & \multirow{2}{*}{ AIC } \\
\hline & Delta1 & rho1 & Delta2 & rho2 & & & \\
\hline 37.063 & 0.938 & 0.902 & 0.996 & 0.994 & 0.996 & 0.044 & 121.063 \\
\hline
\end{tabular}

\section{CONCLUSIONS AND SUGGESTIONS}

In summary, the hypothesis can be verified. The conclusion is city's transportation, the city's construction and people's living standards have some influence on the development of urban economy. We made the following recommendations:

a) Transport should adapt to economic development. Government needs to promote the coordinated development between the economic systems and the transport system. At the same time the government should to strengthen the transport system from the traffic infrastructure construction, transportation, and policy support and other aspects.

b) Governments should be combined with the provinces own construction, control urban growth boundary, regulate the order of the land market, improve the use efficiency of land and encourage the development of land saving industries.

c) Improve level of people's income and stimulate consumption to make the market reach dynamic cycle balance and promote economic growth.

\section{REFERENCES}

[1] Li Wei, Zhu Weina. A Study about the Factors of Regional Economic Development based on Structural Equation Model[J]. Management World, 2014,03:172-173.

[2] Cheng Yan, Mei Shue. Empirical Research on the Relationship between Social Economic Development and County Technology[J]. Science \& Technology Progress and Policy, 2011,11:40-43.

[3] He Weijun, Shen Changgeng, Yuan Liang. The Analysis of the Impact on Physical Capital and Human Capital to Economic Growth based on Structural Equation Model[J]. Business Times, 2013,32:11-13.

[4] He Xiaoqun. Multivariate statistical analysis[M]. China Renmin University Press, 2014,261-278.

[5] Wu Minglong. Structural Equation Modele-The Operation and Application of AMOS[M], Chongqing University Press,2013. 